\title{
Scenarios science needed in UNFCCC periodic review
}

\section{To the Editor - The outcomes of the 25th} meeting of the Conference of the Parties (COP) to the UNFCCC are widely regarded as a disappointment. However, among the decisions that were taken is one of central importance for the UNFCCC's sciencepolicy interface - 'the periodic review of the long-term global goal and of overall progress towards achieving it' is going into its second phase, which is starting in 2020 (ref. ${ }^{1}$ ).

The periodic review is a science-based process under the UNFCCC that dates back to COP16 in Cancun ${ }^{2}$. It is mandated to assess the adequacy of the long-term (temperature) goal in light of the ultimate objective of the UNFCCC: that is, "to prevent dangerous anthropogenic interference with the climate system"3. The first review was held during 2013-2015 and included an extensive dialogue between policy-makers and scientists, termed the Structured Expert Dialogue $(\mathrm{SED})^{4}$, which established that $2{ }^{\circ} \mathrm{C}$ cannot be considered safe ${ }^{4}$. This provided the essential scientific basis for the inclusion of the $1.5^{\circ} \mathrm{C}$ long-term temperature limit in the Paris Agreement ${ }^{5}$.

The periodic review is thus a very powerful process under the UNFCCC and presents an important opportunity for the inclusion of science into climate negotiations. Following the decisions taken by parties in Madrid, the next periodic review is set to begin in "the second half of 2020", with the second SED starting at COP26 in November 2020 (ref. ${ }^{1}$ ).

Compared to the first review, the scope of the second review has been substantially revised. There appears to be no appetite to rewrite the goal agreed in Paris ${ }^{1}$. Instead, it will seek to enhance the understanding of "the long-term global goal and scenarios towards achieving it in the light of the ultimate objective of the Convention" and scientific progress made since the 2013-2015 review.

Including the concept of scenarios in the second review is a step-change in how the temperature goal is assessed under the UNFCCC. Doing so recognises the need to consider our evolving scientific understanding not only of the goal itself, but also of the requirements to get us there. It provides an avenue to discuss the key benchmarks for achieving given temperature limits, such as the timing of net-zero emissions targets ${ }^{6}$, as well as the implications of different interpretations of the Paris Agreement temperature goal, including overshooting the $1.5^{\circ} \mathrm{C}$ long-term limit ${ }^{7}$.

Many emission scenarios in the literature allow warming to overshoot $1.5^{\circ} \mathrm{C}$, employing large-scale carbon dioxide removal to bring temperatures back down. Such need for removals might be associated with substantial negative side effects ${ }^{8}$ and could place undue burden on future generations ${ }^{6}$. Meanwhile, the impacts of overshooting $1.5^{\circ} \mathrm{C}$ may not be reversible, particularly for vulnerable systems such as coral reefs ${ }^{9}$ or wildfire risks ${ }^{8}$ and for systems with a time-lag, such as long-term sea level rise ${ }^{10}$.

As governments undertake the review, careful attention will need to be paid to how "scenarios towards achieving the long-term goal" are classified. Most often, a scenario classified as ' $2{ }^{\circ} \mathrm{C}$ compatible' has a $66 \%$ probability of holding warming below that level, whereas $1.5^{\circ} \mathrm{C}$ scenarios are classified with a mere $50 \%$ probability ${ }^{11}$. The uncertainties underlying these probability estimates are profound, and higher climate sensitivities in a new generation of climate models are a stark reminder that lower probability-high warming outcomes should be all but ruled out ${ }^{12}$. Clear communication of these uncertainties will be essential.

Besides the 'adequacy' theme, the periodic review is tasked to look at "the overall progress made". It will look at "challenges and opportunities for achieving the longterm global goal" and will assess the "overall aggregated effect of the steps taken by Parties". The world is far off track what is needed to achieve the Paris Agreement goals ${ }^{13}$ and fundamental roadblocks in achieving the required transformation still remain, the continued expansion of coal infrastructure being a pertinent example ${ }^{14}$. At the same time, the last few years have seen significant technological progress, and renewable energy sources are already the cheapest sources of electricity in many regions ${ }^{15}$. To make the most of these promising trends will require the right economic, social and financial environments - essential components of a rapid transition to net-zero that the review can help to highlight ${ }^{16,17}$.

Emission levels in 2030 as currently implied by the National Determined Contributions would rule out keeping warming below $1.5^{\circ} \mathrm{C}\left(\right.$ ref. $\left.^{11}\right)$. If substantial improvements in near-term emissions reduction targets are not brought forward this year, the first Global Stocktake in 2023 will probably be too late to significantly affect emissions trajectories during the 2020s. The periodic review and its SED may provide a much-needed science-driven process still in time to inform decisions taken in a decisive decade for global efforts to combat climate change, including on countries' long-term strategies. It also provides a timely opportunity for the Special Reports and the forthcoming Assessment Reports of the IPCC to be directly taken up by the UNFCCC as they are published. It therefore seems worthwhile for the IPCC, international institutions and the scientific community alike to consider carefully the scope of the second periodic review - a science-based process that is linked to the very purpose of the UNFCCC itself.

\section{Carl-Friedrich Schleussner (iD) 1,2 $₫$ and Claire L. Fyson (D)}

${ }^{1}$ Climate Analytics, Berlin, Germany. ${ }^{2}$ Integrative Research Institute on Transformations of Human-Environment Systems (IRI THESys), Humboldt-Universität zu Berlin, Berlin, Germany.

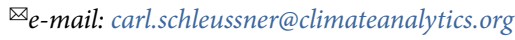

Published online: 9 March 2020

https://doi.org/10.1038/s41558-020-0729-9

References

1. Scope of the Second Periodic Review of the Long-Term Global Goal Under the Convention and of Overall Progress Towards Achieving it FCCC/SB/2017/L.1 (UNFCCC, 2019).

2. The Cancun Agreement FCCC/CP/2010/7/Add.1 (UNFCCC, 2010).

3. United Nations Framework Convention on Climate Change (UNFCCC, 1992).

4. UNFCCC. Report on the Structured Expert Dialogue on the 2013-2015 Review FCCC/SB/2015/INF.1 (UNFCCC, 2015).

5. Schleussner, C.-F. et al. Nat. Clim. Change 6, 827-835 (2016).

6. Rogelj, J. et al. Nature 573, 357-363 (2019).

7. Schleussner, C.-F., Nauels, A., Schaeffer, M., Hare, W. \& Rogelj, J. Environ. Res. Lett. 14, 12 (2019).

8. IPCC: Summary for Policymakers. In Special Report on Climate Change and Land (WMO, 2019).

9. IPCC: Summary for Policymakers. In Special Report on the Ocean and Cryosphere in a Changing Climate (eds Pörtner, H.-O. et al.) (WMO, 2019).

10. Mengel, M., Nauels, A., Rogelj, J. \& Schleussner, C. F. Nat. Commun. 9, 601 (2018)

11. IPCC: Summary for Policymakers. In Special Report on Global Warming of $1.5^{\circ} \mathrm{C}$ (eds Masson-Delmotte, V. et al.) (WMO, 2018).

12. Forster, P. M., Maycock, A. C., McKenna, C. M. \& Smith, C. J. Nat. Clim. Change 10, 7-10 (2020).

13. Governments Still Showing Little Sign of Acting on Climate Crisis (Climate Action Tracker, 2019).

14. Tong, D. et al. Nature 572, 373-377 (2019).

15. Ram, M. et al. J. Clean. Prod. 199, 687-704 (2018).

16. Steckel, J. C. \& Jakob, M. Int. Econ. 155, 19-28 (2018).

17. Farmer, J. D. et al. Science 364, 132-134 (2019). 